\title{
'|||||||||||||||||||||||||||||||||||||||||||||||||||||||||||||||||||||||||.
}

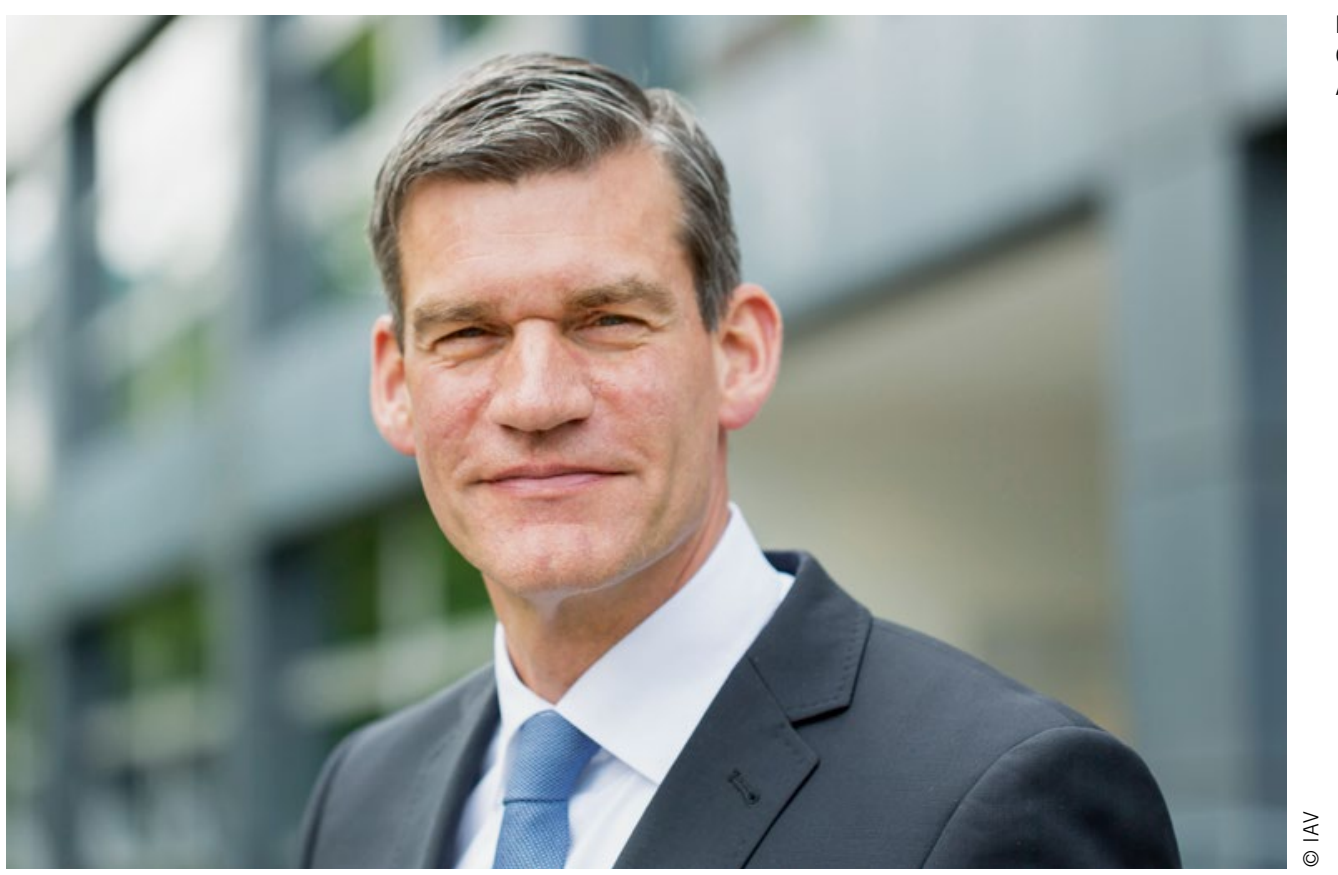

Kai-Stefan Linnenkohl

Geschäftsführer und

Arbeitsdirektor, IAV GmbH

\section{Einmalige Chance nutzen}

Fragt man angehende Ingenieure nach ihren bevorzugten Arbeitgebern, ergibt sich jedes Jahr das gleiche Bild: Automobilhersteller und -zulieferer rangieren in der Gunst des begehrten Nachwuchses ganz weit vorne. Kein Wunder, denn in modernen Fahrzeugen fließen hochaktuelle Entwicklungen zusammen neben neuen Antriebssträngen und Konstruktionsprinzipien auch immer mehr IT-Themen. So sind mittlerweile Softwarespezialisten, die technologisch an vorderster Front arbeiten möchten, bei einem Automobilentwickler bestens aufgehoben.

Allerdings kann auch IAV, die zu den Top 100-Arbeitgebern gehört, bei der Nachwuchsgewinnung die Hände nicht einfach in den Schoß legen. Denn die Automobilentwicklung und damit auch die Anforderungen an unsere Mitarbeiter ändern sich derzeit rasant. Als Engineering-Partner spüren wir das ganz besonders: Immer größere Projektumfänge erfordern von meinen Kollegen neben technischem Wissen zunehmend auch Know-how im Bereich Projektmanagement. Nur so können wir unsere Schnittstellenfunktion zwischen OEM und Zulieferern ausfüllen.

Hinzukommt der wachsende Einfluss der Consumer Elektronik mit ihren deutlich kürzeren Entwicklungszyklen. Hier sind neue Ansätze gefragt, die sich beispielsweise schon in der Softwareentwicklung bewährt haben - ich nenne nur die Stichworte „agiles Entwickeln“ und „agiles Projektmanagement“. Bei IAV haben wir darauf reagiert und ein Digital Lab ins Leben gerufen. Unsere „open-space“-Arbeitsplätze sorgen für eine kreative Umgebung, die wir nicht zuletzt für neue Formate wie „Meetups“, „Hackathons“ und „BarCamps“ nutzen. So können wir in sehr kurzer Zeit ganzheitliche Lösungen entwickeln. Diese neuen Formate fördern den bereichsübergreifenden Wissensaustausch und verändern die Zusammenarbeitskultur im Unternehmen. Maschinenbauingenieure der Fahrwerkentwicklung arbeiten dann mit den Informatikern, die die Cloudanwendung bedienen, kollaborativ zusammen.

Intern begleiten wir diesen Transformationsprozess mit regelmäßigen Weiterbildungen sowie mit neuen Formen des Recruitings. Gerade die nachwachsende Generation von Ingenieuren hat ein klares Bild von ihren Wunscharbeitgebern und den Rahmenbedingungen am Arbeitsplatz. Über Social Media und bei Events, wie der Formula Student, treten wir an Talente heran und überzeugen sie von den Vorzügen der Arbeit bei einem Engineering-Partner - darunter ein breit gefächertes Themenspektrum und die frühzeitige Übernahme von Verantwortung. Für mehr Flexibilität und einer guten Vereinbarkeit von Beruf und Familie sorgt unsere Vereinbarung zum mobilen Arbeiten. Denn eine gute Work-Life-Balance ist für unsere Mitarbeiter genauso wichtig wie Gehalt und Karrierechancen.

Vieles ist bei uns im Moment in Bewegung - in der Fahrzeugtechnik ebenso wie in der Arbeitswelt. Trotzdem macht mir die Zukunft keine Sorgen. Wer seit mehr als 30 Jahren Innovationen in Serie bringt, hat auch genügend Kreativität, um die Transformation der Engineering-Prozesse als einmalige Chance zu nutzen. Darum bin ich mir sicher, dass wir und andere Unternehmen aus der Automobilbranche auch künftig an der Spitze der Arbeitgeberrankings stehen werden. 